\title{
OJS OPEN

\section{EDUCAÇÃO AMBIENTAL NA ESCOLA: A GEOGRAFIA COMO UMA FERRAMENTA DA PRÁTICA INTERDISCIPLINAR}

\author{
Helena Maria Beling ${ }^{1}$, Janete Webler Cancelier ${ }^{2}$, Michele Hennig \\ Vestena $^{3}$, Josiane Oliveira de Campos ${ }^{4}$
}

${ }^{1}$ Discente de doutorado no Programa de Pós-graduação em Geografia (PPGEO) da Universidade Federal de Santa Maria (UFSM). E-mail: helenabeling2015@gmail.com-ORCID iD: http://orcid.org/0000-00026356-3594;

${ }^{2}$ Doutora em Geografia pela Universidade Federal de Santa Maria (UFSM). E-mail: janetewc@gmail.com - ORCID iD: http://orcid.org/0000-0002-4850-5492;

${ }^{3}$ Discente de mestrado no Programa de Pós-graduação em Geografia (PPGEO) da Universidade Federal de Santa Maria (UFSM). E-mail: michele-vestena@hotmail.com. ORCID iD: http://orcid.org/0000-00019421-5376;

${ }^{4}$ Discente de graduação em Geografia - Licenciatura pela Universidade Federal de Santa Maria (UFSM). E-mail: josianecampos.geo@gmail.com-ORCID iD: http://orcid.org/0000-0001-8899-5564.

Artigo recebido em 16/06/2020 e aceito em 03/08/2020

\begin{abstract}
RESUMO
O presente trabalho se propõe a apresentar discussões referentes à importância da educação ambiental nas escolas de ensino básico, buscando compreender os parâmetros legais em que a educação ambiental está amparada, a importância da prática interdisciplinar e a relação da educação ambiental com o ensino de Geografia. Para demonstrar como a temática ambiental pode ser trabalhada na disciplina de Geografia são apresentadas oficinas práticas desenvolvidas com alunos da Escola Estadual de Ensino Fundamental Dom Érico Ferrari, localizada no município de Nova Palma/RS. A pesquisa foi realizada a partir da abordagem qualitativa e entre os instrumentos utilizados para obtenção dos dados incluiu-se a pesquisa bibliográfica, documental e de campo. A educação ambiental está evidenciada em leis, programas e normas da educação, devendo, nas instituições de ensino, estar presente de forma articulada em todos os níveis e modalidades do processo educativo. Verificou-se que a educação ambiental se consolida na escola como prática pelo trabalho articulado, realizado entre as distintas áreas do conhecimento tomando como referência a realidade e as relações que se estabelecem a nível local e sua interface com a dinâmica global.
\end{abstract}

Palavras-chave: Educação; Educação Ambiental; Ensino de Geografia; Escola; Interdisciplinaridade.

\begin{tabular}{lllll}
\hline Beling, Cancelier, & Vestana & e de & ISSN 2594-9616 & 116 \\
Campos, 2020 & & & &
\end{tabular}




\title{
ENVIRONMENTAL EDUCATION AT SCHOOOL: GEOGRAPHY AS AN INTERDISCIPLINARY PRACTICE TOOL
}

\begin{abstract}
This paper aims to present discussions referred to the environmental education importance at elementary schools, seeking to understand the legal parameters in which environmental education is supported, the importance of interdisciplinary practice and the relationship between environmental education and Geography teaching. To demonstrate how the environmental theme can be worked with Geography, practical workshops developed with students from the Dom Érico Ferrari State Elementary School, located in Nova Palma/RS, are presented. The research was made from a qualitative approach and the instruments utilized to obtain the data are bibliographic, documentary and field research. Environmental education is evidenced in laws, programs and education norms, and in educational institutions, it should be present in an articulated manner at all levels and modalities of the educational process. It was verified that the environmental education is consolidated at schools as a practice through articulated work, made with different areas of knowledge, taking as reference the reality and the relationships established at a local level and its interface with global dynamics.
\end{abstract}

Keywords: Education; Environmental Education; Geography Teaching; School; Interdisciplinarity.

\section{LA EDUCACIÓN AMBIENTAL EN LA ESCUELA: LA GEOGRAFÍA COMO HERRAMIENTA EN LA PRÁCTICA INTERDISCIPLINARIA}

\begin{abstract}
RESUMO
Este artículo propone presentar discusiones sobre la importancia de la educación ambiental en las escuelas primarias, buscando comprender los parámetros legales sobre los que se sustenta la educación ambiental, la importancia de la práctica interdisciplinaria y la relación entre la educación ambiental y la enseñanza de la Geografía. Para demostrar cómo se puede trabajar el tema ambiental en la disciplina de Geografía, se presentan talleres prácticos desarrollados con estudiantes de la Escuela Primaria Estatal Dom Érico Ferrari, ubicada en el municipio de Nova Palma / RS. La investigación se realizó desde el enfoque cualitativo y entre los instrumentos utilizados para la obtención de los datos se incluyó la investigación bibliográfica, documental y de campo. La educación ambiental se evidencia en las leyes, programas y normas de educación, y en las instituciones educativas debe estar presente de manera articulada en todos los niveles y modalidades del proceso educativo. Se encontró que la educación ambiental se consolida en la escuela como una práctica por el trabajo articulado, realizado entre las diferentes áreas del conocimiento tomando como referencia la realidad y las relaciones que se establecen a nivel local y su interfaz con las dinámicas globales.
\end{abstract}

Palabras llave: Educación. Educación ambiental. Enseñanza de la geografía. Colegio. Interdisciplinariedad. 


\section{INTRODUÇÃO}

A Educação é um direito social, deve ser garantida com qualidade para todos os indivíduos. As escolas possuem significativo papel na formação da sociedade, na medida em que auxiliam na preparação e formação do indivíduo para sua emancipação pessoal e social. Neste contexto, compreender o papel que a educação exerce na sociedade, com suas práticas e ações pedagógicas, é fundamental para o estabelecimento de ações e políticas educacionais.

O presente trabalho apresenta como tema a importância atribuída à educação ambiental nos espaços escolares. Bem como, o papel da interdisciplinaridade e dos múltiplos saberes e conhecimentos perante a consolidação de práticas ambientais no ambiente escolar.

A temática ambiental está evidenciada em leis, programas e normas da educação. Nesse sentido, deve ser trabalhada por todas as áreas do conhecimento. A escola é um espaço social, onde muitas pessoas convivem, assimilam aprendizados e socializam conhecimentos. Assim, o espaço escolar é adequado para, por exemplo, trabalhar projetos referentes à saúde e a educação ambiental.

Partindo das presentes premissas, essa proposta investigativa objetiva compreender a importância da educação ambiental nas escolas de ensino básico. Para compreender a dimensão da questão central, o texto apresenta discussões referentes: a educação ambiental amparada nos documentos educacionais oficiais; a educação ambiental; a educação ambiental e o ensino de Geografia e as oficinas didáticas trabalhando a compostagem e a colmeia da sustentabilidade, realizadas com alunos da escola Estadual de Ensino Fundamental Dom Érico Ferrari, localizada no município de Nova Palma/RS.

O trabalho apresenta uma temática relevante, pois trata de um tema atual para a educação. Possibilitar que o aluno compreenda seu papel perante a sociedade e os mecanismos presentes que provocam profundas mudanças ambientais, as quais se refletem de distintas formas no mais diferenciados espaços, os quais, os espaços de vivência em que os alunos estão inseridos, incentivando a formação de cidadãos conscientes frente às questões sociais e ambientais, visando práticas mais sustentáveis.

\begin{tabular}{lllll}
\hline Beling, Cancelier, & Vestana & e de & ISSN 2594-9616 & 118 \\
Campos, 2020 & & & &
\end{tabular}


Considerando que a Geografia tem contribuição importante na temática ambiental, pois a sociedade e natureza são temas de seu interesse. A ciência geográfica tem seu olhar voltado para as questões ambientais, como, a sociedade de consumo, uso desenfreado dos recursos naturais, busca pela sustentabilidade, mostrando de forma clara a relação entre aos atores sociais e as transformações no espaço geográfico. Assim, a relação da Geografia com a educação ambiental é de suma importância para a conscientização dos sujeitos sobre a necessidade de preservar a natureza e garantir qualidade de vida. A Geografia tem encontrado como alternativa, por exemplo, à inclusão de projetos e oficinas didáticas, fazendo dessas atividades suas ferramentas pedagógicas.

\section{PROCEDIMENTOS METODOLÓGICOS}

A pesquisa caracteriza-se pela abordagem qualitativa e apresenta uma análise interpretativa e descritiva, que se propõe a traduzir e expressar o fenômeno estudado. Para seu desenvolvimento, utilizamos a pesquisa bibliográfica, documental, de campo e as análises. Inicialmente, um levantamento bibliográfico com a leitura de artigos científicos e livros relacionados às questões de natureza teórica que abordem a temática. A partir deste, apresenta-se, de forma sucinta, explanações acerca da educação ambiental e do ensino de geografia.

No segundo momento, de fase exploratória, a pesquisa documental. O levantamento de dados e informações obtidos na Constituição Federal (CF) de 1988, na Lei de Diretrizes e Bases da Educação (LDB) de 1996, nos Parâmetros Curriculares Nacionais (PCNs) de 1997, na Lei da Política Nacional de Educação Ambiental (PNEA) de 1999 e nas Diretrizes Curriculares Nacionais (DCNs) para a Educação Ambiental de 2012. A partir destes tornou-se possível contextualizara educação ambiental inserida no contexto escolar.

Os dados qualitativos foram obtidos no ano de 2019, com as oficinas: trabalhando a compostagem e colmeia da sustentabilidade, realizadas com um total de 33 alunos da Escola Estadual de Ensino Fundamental Dom Érico Ferrari, localizada no município de Nova Palma/RS. Cabe enfatizar que, a Escola em questão é do campo.

A oficina trabalhando a compostagem foi realizada com a turma do $9^{\circ}$ ano, que possuía um total de 12 alunos. A oficina foi dividida em duas etapas, a primeira de caráter

\begin{tabular}{lllll}
\hline Beling, Cancelier, Vestana & $e$ & de & ISSN 2594-9616 & 119 \\
Campos, 2020 & & & &
\end{tabular}


teórico, buscava averiguar, através de perguntas informais, os conhecimentos prévios dos educandos sobre a temática da compostagem. Sequencialmente, foi apresentado conceitos, sobre o histórico e o processo de compostagem com o apoio do quadro. Após, foi realizada uma atividade prática, onde cada aluno construiu uma mini composteira doméstica utilizando: garrafa pet, areia, restos de alimentos, cascas de frutas e serragem. Logo após, a composteira foi levada para suas residências. Por fim, foi realizada uma nova conversa para verificar se ocorreram avanços em relação aos resultados obtidos no primeiro momento.

A segunda oficina nomeada de "colmeia da sustentabilidade" foi aplicada para 21 alunos distribuídos entre Pré-escola e turmas do $1^{\circ}$ ao $4^{\circ}$ ano. A oficina foi realizada em três etapas. A primeira fase foi de caráter teórico, a partir de uma roda de conversa foram levantadas questões sobre a importância das abelhas para o meio ambiente e práticas de educação ambiental. Na segunda etapa, foi trabalhado um filme que demonstrava o risco que as abelhas estão sofrendo em razão do uso indiscriminado de agrotóxicos. A terceira etapa, de caráter prático, cada turma foi estimulada a desenvolver alguma atividade vinculada à temática como: desenhos para pintar, desenho livre, cruzadinha e labirinto, construção de alguns objetos e brinquedos com materiais recicláveis como caixas de ovos, rolos de papel higiênico, jornais. Ao término da oficina, construiu-se um grande mural onde ficaram expostos todos os trabalhos feitos pelos alunos durante a oficina.

\section{A EDUCAÇÃO AMBIENTAL AMPARADA NOS DOCUMENTOS EDUCACIONAIS OFICIAIS}

$\mathrm{A} \mathrm{CF}$, em seu $6^{\circ}$ artigo, assegura que a educação é um direito social e deve ser ofertada com qualidade a todos os cidadãos. O mesmo documento, em seu artigo 225 , destaca que todos têm direito a um ambiente ecologicamente equilibrado. Ainda em seu inciso VI, salienta que Educação Ambiental é um direito constitucional previsto para todos os cidadãos brasileiros e que "[...] a educação ambiental deve ser ofertada em todos os níveis de ensino, bem como a conscientização pública para a preservação do meio ambiente" (BRASIL, 1988, p. 98). Ainda que pouco presente nas práticas didáticas pedagógicas atualmente, já estava prevista desde 1988.

\begin{tabular}{lllll}
\hline Beling, Cancelier, Vestana & $e$ & de & ISSN 2594-9616 & 120 \\
Campos, 2020 & & & &
\end{tabular}


Por sua vez, a LDB em seu artigo 26 específica que a educação infantil, o ensino fundamental e ensino médio "[...] devem ter base nacional comum, a ser complementada, em cada sistema de ensino e em cada estabelecimento escolar, por uma parte diversificada, exigida pelas características regionais e locais da sociedade, da cultura, da economia e dos educandos" (BRASIL, 1996, p. 09).

A partir deste contexto, tem-se a possibilidade de vincular os conteúdos as especificidades locais. No que tange especialmente a educação ambiental, a LDB, em seu artigo 26, inciso $7^{\circ}$ aponta que "Os currículos do ensino fundamental e médio devem incluir os princípios da proteção e defesa civil e a educação ambiental de forma integrada aos conteúdos obrigatórios" (BRASIL, 1996, p. 10). O que exige dos professores o conhecimento da realidade em que a escola está inserida, bem como dos problemas que de distintas formas assolam a sociedade. Tomando como base esse conhecimento, tornase possível vincular os conteúdos obrigatórios com a temática ambiental.

Sequencialmente, foram criados os PCNs para o Ensino Fundamental e Ensino Médio, os quais foram divididos em três volumes, sendo: $1^{\circ}$ a $4^{\circ}$ séries, $5^{\circ}$ a $8^{\circ}$ séries e Ensino Médio. A partir destes parâmetros se estabelecem diretrizes para orientar as práticas pedagógicas dos professores em cada disciplina (BRASIL, 1997). Também evidenciam a possibilidade de adaptar os conteúdos as especificidades locais e que estes podem trabalhados a partir dos temas transversais de: saúde, meio ambiente, pluralidade cultural, orientação sexual e ética. Tais temas são considerados pertinentes e devem ser abordados pelo conjunto das disciplinas que compõem a grade curricular.

Os PCNs apontam “a educação como elemento indispensável para a transformação da consciência ambiental" (BRASIL, 1997). Ainda, que a educação ambiental, deve incorporar aspectos sociais, econômicos, éticos e políticos. Nesse sentido, orientam que:

A principal função do tema Meio Ambiente na escola é contribuir para a formação de cidadãos conscientes, aptos a decidir e atuar na realidade socioambiental de um modo comprometido com a vida, com o bem-estar de cada um e da sociedade, local e global. Para isso é necessário que, mais do que informações e conceitos, a escola se proponha a trabalhar com atitudes, com formação de valores, com o ensino e aprendizagem de procedimentos (BRASIL, 1997, p. 187). 
A partir do contexto apresentado, fica evidente que a escola possui significativo papel no sentido de, organizar e proporcionar um ambiente favorável para as discussões e reflexões a respeito das questões ambientais, bem como, das ações a serem implementadas. Este processo deve ocorrer pela participação ativa de todos os sujeitos (alunos, pais, professores, funcionários, entre outros), que compõem a comunidade escolar. Tendo em vista que, os resultados alcançados poderão ser ampliados se toda a comunidade escolar "assumir os mesmos objetivos, pois eles se concretizarão em diversas ações que envolverão todos, cada um na sua função" (BRASIL, 1997, p. 191).

Todavia, as ações desenvolvidas na perspectiva da temática ambiental também devem ser construídas pelo trabalho em conjunto tomando como base o viés interdisciplinar, o qual inclusive já é previsto nos PCNs. A escola a partir do currículo e orientações elaboradas em conjunto pode implementar práticas que visem propiciar uma transformação social no cenário em que se encontra inserida. Ainda possibilitar que, os educandos construam a visão da totalidade das questões ambientais, onde, nesse processo, cada docente seja agente da interdisciplinaridade exigida pelo tema (BRASIL, 1997).

Logo, a temática educação ambiental é interdisciplinar e deve ser trabalhada através da transversalidade. "Trabalhar de forma transversal significa buscar a transformação dos conceitos, a explicitação de valores e a inclusão de procedimentos, sempre vinculados à realidade cotidiana da sociedade, de modo que obtenha cidadãos mais participantes" (BRASIL, 1997). Neste sentido, em cada área específica o conteúdo deve ser adequado.

\footnotetext{
Nos PCNs os conteúdos de Meio Ambiente foram integrados às áreas, numa relação de transversalidade, de modo que impregne toda a prática educativa e, ao mesmo tempo, crie uma visão global e abrangente da questão ambiental, visualizando os aspectos físicos e histórico-sociais, assim como as articulações entre a escala local e global desses problemas (BRASIL, 1997, p. 193).
}

Neste contexto, em 27 de abril de 1999, é criada a Lei no 9.795 que dispõe sobre a educação ambiental e institui PNEA. Em seu artigo $1^{\circ}$ trata que educação ambiental faz referência aos "[...] processos por meio dos quais o indivíduo e a coletividade constroem valores sociais, conhecimentos, habilidades, atitudes e competências voltadas para a conservação do meio ambiente, bem de uso comum do povo, essencial à sadia qualidade de vida e sua sustentabilidade" (BRASIL, 1999, p. 01).

\begin{tabular}{lllll}
\hline Beling, Cancelier, Vestana & e de & ISSN 2594-9616 & 122 \\
Campos, 2020 & & & &
\end{tabular}


No que tange aos níveis de ensino e modalidades, estabelece em seu artigo $2^{\circ}$ que a educação ambiental é componente assegurado em todos os níveis, sejam eles em caráter formal e não-formal do processo educativo. A educação ambiental deve ser desenvolvida com base em uma "[...] prática educativa integrada, contínua e permanente em todos os níveis e modalidades do ensino formal” (BRASIL, 1999, p. 3).

Em relação a formação de professores o PNEA, em seu artigo 11, salienta que a dimensão ambiental deve constar nos currículos dos cursos de formação de professores. Em decorrência as instituições de ensino precisam reorganizar seus currículos, no sentido de inserir a educação ambiental, não como uma disciplina isolada e sim como um tema integrador a ser desenvolvido de forma articulada e contextualizada em todas as disciplinas. No que se refere aos professores que já se encontram lecionando o documento evidência que estes devem receber formação complementar em suas áreas de atuação, com o propósito de atender adequadamente ao cumprimento dos princípios e objetivos da PNEA. Apesar de estar prevista a necessidade de uma formação adequada aos professores na PNEA, poucos avanços ocorreram neste sentido.

Em decorrência, em junho de 2012 foram criadas as DCNs para a Educação Ambiental. Que, em seu artigo $2^{\circ}$, aborda que a educação ambiental faz parte da educação, sendo uma atividade intencional da prática social, "[...] que deve imprimir ao desenvolvimento individual um caráter social em sua relação com a natureza e com os outros seres humanos". No artigo $3^{\circ}$ enfatiza que a Educação Ambiental “[...] visa a construção de conhecimentos, desenvolvimento de habilidades, atitudes e valores sociais, ao cuidado com a comunidade de vida, a equidade socioambiental, e a proteção do meio ambiente natural e construído" (BRASIL, 2012, p. 27). O artigo $7^{\circ}$ evidencia que a Educação Ambiental é um componente integrante, essencial e permanente, que deve estar presente de forma articulada, cabendo às instituições de ensino, promovê-la integradamente nos seus projetos institucionais e pedagógicos. Neste sentido, ao se referir à organização curricular, as DCNs chamam as instituições educacionais a assumirem o compromisso com a educação ambiental.

A partir do contexto apresentado, observa-se que a temática de educação ambiental está presente em distintos documentos oficiais, as quais enfatizam que, o ambiente escolar se caracteriza enquanto um importante espaço para a conscientização das questões ambientais. Ainda que, a educação ambiental deve ser introduzida em todos

Beling, Cancelier, Vestana e de $\quad$ ISSN 2594-9616 123


os conteúdos de maneira interdisciplinar, como o meio para sensibilizar e conscientizar os educandos para um convívio harmônico e saudável com o meio ambiente.

A sala de aula se constitui como um espaço de excelência para trabalhar a educação ambiental. Todavia, faz-se necessário que os docentes, a partir de suas práticas didáticas/pedagógicas utilizem habilidades no sentido de construir o conhecimento elaborando relações entre conteúdos curriculares, questões ambientais e o cotidiano dos educandos. Este objetivo pode ser potencializado pela elaboração e desenvolvimento de projetos e atividades vinculados a questões socioambientais, como os apresentados neste estudo.

Aprendemos com base no que já conhecemos, que a interação entre conhecimentos prévios e o novo possibilita um conhecimento processual, ou seja, uma aprendizagem significativa. $\mathrm{Na}$ escola, em relação às questões ambientais, esta aprendizagem pode ser construída pelo trabalho que envolve diferentes escalas de análise, parte-se do local para o global, partindo das questões mais especificas, de domínio da realidade dos educandos, para as questões mais complexas e abrangentes.

Trabalhar a educação ambiental nas escolas é despertar nos educandos e na comunidade escolar, a consciência da necessidade da preservação e utilização racional dos recursos. A construção de uma sociedade igualitária perpassa pelo comprometimento de transformar as práticas, no entendimento de que o futuro depende do equilíbrio entre sociedade e natureza.

\section{EDUCAÇ̃̃O AMBIENTAL}

A preocupação com a dimensão ambiental se intensificou na sociedade contemporânea. Os problemas ambientais estão presentes, em diferentes intensidades, nos mais distintos espaços. Tal fenômeno tem fomentado o incentivo às ações de educação ambiental que vislumbrem a conscientização ambiental e a diminuição dos problemas ambientais.

Trabalhos publicados recentemente, principalmente em periódicos, têm demonstrado que a educação ambiental deve ser compreendida e concretizada a partir de um conjunto de conhecimentos referenciais e concepções. Nesse contexto, os referenciais sociológicos, filosóficos e sociais, bem como concepções políticas, econômicas e

\begin{tabular}{lllll}
\hline Beling, Cancelier, Vestana & $e$ & de & ISSN 2594-9616 & 124
\end{tabular}


culturais (CARVALHO, 2000; TOZONI-REIS, 2008), devem ser considerados conjuntamente com a realidade ambiental de cada espaço. A partir da compreensão da totalidade torna-se possível elaborar ações de educação ambiental adequadas a demandas especificas que podem ser locais e ou regionais, bem como estaduais e federais.

Concorda-se com Freire (2002), que a educação ambiental precisa ser entendida e realizada enquanto prática libertadora e transformadora, e, suas ações realizadas a partir do contexto social em que cada escola está inserida, articulando o saber popular e o saber crítico e científico mediados pelas experiências do mundo. Desta forma, o papel da escola se efetiva, na medida em que, a discussão da educação ambiental se articule ao trabalho interdisciplinar, aos diferentes conteúdos curriculares e à realidade do contexto social em que a escola está inserida.

Cada disciplina com suas abordagens específicas e conteúdos programáticos pode contribuir para a conscientização e realização de práticas sustentáveis. Ao realizar o trabalho de educação ambiental articulado as demandas da comunidade, a escola contribui com o desenvolvimento de práticas sustentáveis.

A participação da comunidade escolar, a relação de trocas e a construção conjunta de conhecimentos e aprendizados, garantem um ganho qualitativo para a efetivação da educação ambiental. Na medida em que os sujeitos passam a compreender, de forma crítica, que os problemas ambientais são resultantes das relações de desequilíbrios estabelecidos entre sociedade e natureza.

Guimarães (2013, p. 30371), menciona que “[...] mudar a realidade passa por transformar as formas de estar no mundo individualmente e nas práticas sociais, em novas relações, novos modos de produzir e consumir". Assim, a educação e o educador têm papel fundamental nesses processos de transformação. $O$ educador, ao romper com estruturas educacionais tradicionais, reflete em uma prática consciente de intervir na realidade, essa práxis pedagógica se reflete em espaços formativos diferenciados.

Logo, a partir do contexto apresentado, entende-se que a educação ambiental, em suas práticas e ações pedagógicas educativas, pode proporcionar um olhar amplo e crítico aos educandos sobre os problemas ambientais, visando a compreensão dos processos de degradação dos recursos naturais, bem como atitudes sustentáveis.

No que diz respeito à formação de professores, considera-se ser necessário que a educação ambiental esteja presente na formação inicial e continuada. Trazendo, dessa

Beling, Cancelier, Vestana e de $\quad$ ISSN 2594-9616 125 
maneira, ao conteúdo pedagógico, a política da educação ambiental, a legislação e gestão ambiental e suas inter-relações com a práxis pedagógica.

\title{
A EDUCAÇÃO AMBIENTAL E O ENSINO DE GEOGRAFIA
}

A Geografia é a ciência que se dedica ao estudo das relações entre a sociedade e natureza, ocorridas em distintos espaços-tempo. Busca compreender como as mudanças se materializam, transformando o espaço geográfico.

Segundo Pontuschka, Paganelli e Cacete (2009, p. 134), “[...] a Geografia possui teorias, métodos e técnicas que podem auxiliar na compreensão de questões ambientais e no aumento da consciência ambiental das crianças, jovens e professores”. Completando, Cavalcanti (2010, p. 368), aponta que “[...] os professores de Geografia têm o desafio constante de desenvolver um trabalho docente que resulte em uma aprendizagem significativa para os alunos".

No contexto, na educação básica a Geografia auxilia e motiva os educandos a observar, analisar, interpretar e pensar de maneira crítica as relações existentes nos diferentes espaços entre sociedade-natureza, as transformações, as desigualdades, as contradições, bem como, tantos outros aspectos que dizem respeito à produção do espaço. Para Callai (2013, p. 136), o papel da geografia é:

\begin{abstract}
[...] facilitar ao aluno o entendimento de que aquilo que ele está estudando tem a ver com sua vida experienciada cotidianamente, não correspondendo a coisas distantes abstratas. E isso tem que ser feito de modo que o aluno se sinta parte integrante daquilo que está estudando, pois o que nos interessa é, por meio de conhecimento de mundo e de vida, formar o cidadão dando ao aluno as condições de reconhecer-se como sujeito que tem uma história, que tem um conhecimento prévio do mundo e que é capaz de construir o seu conhecimento. Significa compreender a sociedade em que vive, a sua história, e o espaço por ela produzido como resultados da vida dos homens. O desafio aos professores se refere a como aprender a ensina a ler o mundo, a realidade em que vivemos, para que o aluno faça também.
\end{abstract}

A escola sempre esteve interligada à função de propiciar aos educandos "a elaboração de um imaginário, assim como a definição de valores, comportamentos e ideias" que permeiam e desenham a sociedade. Além disso, historicamente, o ambiente escolar é visualizado como local onde os "alunos aprendem determinados conteúdos

\begin{tabular}{llllll}
\hline Beling, Cancelier, Vestana & $e$ & de & ISSN 2594-9616 & 126 \\
Campos, 2020 &
\end{tabular}


fundamentais para o reconhecimento do sentido de pertencimento e de identidade do indivíduo com o território" (FERRAZ, 2011, p. 173).

Partindo dessa perspectiva, o ensino de geografia, em especial, cumpre papel fundamental no que diz respeito ao processo de ensino-aprendizagem do educando frente à interpretação e preservação do lugar. Permitindo, desta forma, que uma análise crítica da realidade, incentivando-os a se posicionar de forma propositiva diante de problemáticas, com consciência das responsabilidades, dos seus direitos e deveres sociais, com o intuito de efetivamente tornar o aluno agente de mudanças desejáveis para a sociedade (NETO, BARBOSA, 2010, p. 161).

Desta maneira, a Geografia apresenta em seus estudos importantes contribuições a Educação Ambiental. Tomando como referência a análise pelo viés da dialética tornase possível compreender as transformações decorrentes das relações entre sociedade e natureza e como estas se materializam no espaço geográfico. Essas relações quando trabalhadas com os educados em todos os níveis e modalidades de ensino da educação básica, bem como, no ensino superior, especificamente no curso de Geografia, possibilitam desenvolver habilidades para a compreensão da realidade a partir de uma visão dotada de criticidade.

Na dialética da relação sociedade e natureza, a práxis pedagógica deve atuar no sentido de possibilitar a construção crítica da consciência dos educandos, tomando como referência o espaço local e suas relações ao contexto mundial. A partir da Geografia, estas relações podem ser compreendidas por meio da dinâmica dos fatores naturais, sociais, econômicos e políticos.

No que se refere aos problemas ambientais, a sociedade precisa entender que os mesmos, tanto em áreas urbanas como em áreas rurais, envolvem relações que se estabelecem entre fatores físico-naturais e sociais (MORAES, 2013, p. 14). Junto a isso, o desenvolvimento do ensino de geografia tem a característica particular de ser facilmente relacionável com outras ciências, propiciando atividades que fujam da fragmentação do saber e da "aprendizagem mecânica" (NETO, BARBOSA, 2010, p. 162), cuja definiç̧ão pode ser entendida como aprender sem fazer ligações verdadeiras com os saberes cotidianos e outros conhecimentos, ou seja, com a ausência de interdisciplinaridade.

O ensino da Geografia contribui no reconhecimento das características da organização do espaço, das tecnologias associadas a essa organização e suas 
consequências ambientais. Permitindo que os educandos conheçam as implicações ambientais e físicas na qualidade de vida (BRASIL, 1997). O ensino, em geral, só é verdadeiramente eficaz quando se torna significativo para o educando, "adotando uma postura crítico-reflexiva, como o próprio currículo contempla e anuncia" (BOTÊLHO, et al, 2016, p. 127).

Nos últimos anos, correlacionado às mudanças que a geografia vem sofrendo "procurando pensar qual é o seu papel na sociedade, constituindo-se de novos conteúdos, reformulando outros já existentes de grande importância, questionando os métodos utilizados [...]" (FERREIRA, et al, 2011, p. 02), e com um debate maior sobre a necessidade de diálogo entre a teoria e prática, tornou-se emergente metodologias que desencadeiam essa função. Desta forma, as oficinas didáticas se tornaram uma ferramenta pedagógica das disciplinas para relacionar os conteúdos programáticos, suas funções e a relação destas no ambiente escolar e no cotidiano dos alunos (BRAGA, 2011, p. 12946). Justamente na aplicabilidade de práticas que formam o ser pensante e o conhecimento com significância é que:

[...] desponta a educação ambiental, como meio para tornar as práticas pedagógico-didáticas, em Geografia, dinâmicas, reflexivas e enviesadas pela realidade dos sujeitos/alunos que estão inseridos no processo, de modo a construir o senso de cidadania, que é, de fato, o objetivo central desta disciplina na escola, segundo os Parâmetros Curriculares Nacionais (BRASIL, 1998), a partir da compreensão e da discussão acerca da complexidade da relação e dos aspectos que norteiam e surgem através da relação homem-meio/sociedadenatureza" (BOTÊLHO, et al, 2016, p. 127).

Nesse sentido, as práticas pedagógicas em geografia - especialmente na geografia crítica, qual tem como um de seus ideais a preocupação com a preservação do meio ambiente, ou seja, a ocupação ou exploração irregular antrópica no contexto do espaço natural - ganham com a educação ambiental a ferramenta e possibilidade de ensino, cumprindo, desta forma, sua "função" escolar.

\section{OFICINAS DIDÁTICAS: TRABALHANDO A COMPOSTAGEM E COLMEIA DA SUSTENTABILIDADE}

A busca pela conscientização ambiental perpassa pela educação ambiental. A partir destes, torna-se possível desenvolver práticas reflexivas visando a conscientização

\begin{tabular}{lllll}
\hline Beling, Cancelier, Vestana & $e$ & de & ISSN 2594-9616 & 128 \\
Campos, 2020 & & & &
\end{tabular}


e a conservação dos recursos naturais. O modo como as pessoas se apropriaram dos espaços e os ressignificam, também devem ser observados, tendo em vista que, estas inter-relações se materializam de distintas formas na paisagem.

Considerando o contexto contemporâneo em que a escola se encontra é essencial que os processos de ensino-aprendizagem também estejam adequados aos propósitos da educação ambiental. Mediante indagações e reflexões e pela articulação entre teorias e práticas, torna-se possível compreender com maior aprofundamento tal questão. $\mathrm{O}$ professor e o futuro professor devem, continuadamente, aprender e refletir criticamente sobre suas práticas pedagógicas, no sentido de que estas, dialoguem com o ambiente social dos educandos, bem como, destacar o papel de cada indivíduo perante o cenário ambiental.

Desse modo, as escolas possuem um papel central, na medida em que, a partir de suas práticas pedagógicas podem potencializar as ações de educação ambiental. Neste contexto, se inserem as oficinas "Trabalhando a compostagem" e "Colmeia da sustentabilidade", realizadas no ano de 2019, com alunos da Escola Estadual de Ensino Fundamental Dom Érico Ferrari, a qual se caracteriza enquanto escola do campo.

Esta Escola organiza os saberes escolares, nas diferentes áreas do conhecimento a partir da realidade no e do campo. Possibilita que os alunos reflitam sobre a importância da preservação ambiental para o desenvolvimento sustentável do seu local como parte integrante do espaço geográfico, através de palestras, visitas a ambientes degradados e o diálogo com a comunidade do campo (PPP, 2017). Sua grade curricular está embasada em escolhas que representam conteúdos vinculados a espaços e tempos que devem ser contemplados, entre os quais o espaço local. Em sua concepção teórico-metodológica prevê a possibilidade de realização de ações e práticas que venham a auxiliar no desenvolvimento de sujeitos críticos e atuantes perante a realidade presente.

As atividades desenvolvidas na oficina "Trabalhando a compostagem", colaborou nas ações do Projeto "horta na escola"i realizado com a turma do $9^{\circ}$ ano. "Colmeia da sustentabilidade", auxiliou com o Projeto "o mel e suas utilidades" ii realizado com as turmas da Pré-escola e do $1^{\circ}$ ao $4^{\circ}$ ano. Ambos, se caracterizam enquanto projetos interdisciplinares de educação ambiental, que preveem ações relacionando à valorização do campo a preservação e manutenção ambiental.

\begin{tabular}{lllll}
\hline Beling, Cancelier, Vestana & $e$ & de & ISSN 2594-9616 & 129 \\
Campos, 2020 & & & &
\end{tabular}


Revista Ensino de Geografia (Recife) V. 3, No. 2, 2020

DOI: https://doi.org/10.38187/regeo2020.v3n2id246196

Os temas de cada projeto são definidos a partir da vivência dos educandos. Buscam potencializar a construção do conhecimento individual e coletivo, a partir dos princípios do Projeto Político Pedagógico (PPP) da Escola. Para auxiliar no desenvolvimento dos projetos são aplicadas oficinas práticas como as citadas. As atividades foram realizadas no horário de aula dos educandos, cada oficina ocorreu em um único turno. Para cada oficina foi construído um plano de aula, onde estavam previstas todas as fases e ações a serem efetivadas, bem como os materiais necessários. As oficinas propostas foram realizadas pelas autoras de forma autônoma e voluntária, sem nenhum recurso financeiro público.

A oficina "Trabalhando a Compostagem" foi realizada a partir do tema a compostagem doméstica, tomando como referência conhecimentos teóricos da Geografia acerca do uso racional dos recursos naturais, da destinação correta dos resíduos e da sustentabilidade. As atividades foram desenvolvidas entre parte teórica e prática.

$\mathrm{Na}$ etapa teórica, foram apresentadas discussões sobre compostagem, decomposição dos alimentos, a importância da compostagem para os cultivos agrícolas, os benefícios e aspectos de sustentabilidade. Os educandos foram instigados a expor seus conhecimentos sobre tais questões. O objetivo foi realizar uma discussão reflexiva e demonstrar que cada um poderia destinar de forma adequada os resíduos orgânicos produzidos nas residências, contribuindo tanto para a diminuição dos impactos ambientais quanto na redução de gastos com a aquisição de insumos, considerando que, o seu resíduo orgânico transformado em húmus, pode ser empregado como adubo, já que são filhos de agricultores.

Posteriormente, na parte prática, os educandos foram divididos em dois grupos permitindo assim, que acompanhassem sequencialmente todos os passos da construção de mini composteiras doméstica com garrafas pet. A partir desta etapa, os educandos verificaram ser possível realizar a compostagem em uma pequena escala, utilizando materiais recicláveis colaborando para a sustentabilidade. A figura 1 demonstra um mosaico de imagens com as diferentes etapas realizadas na oficina. 


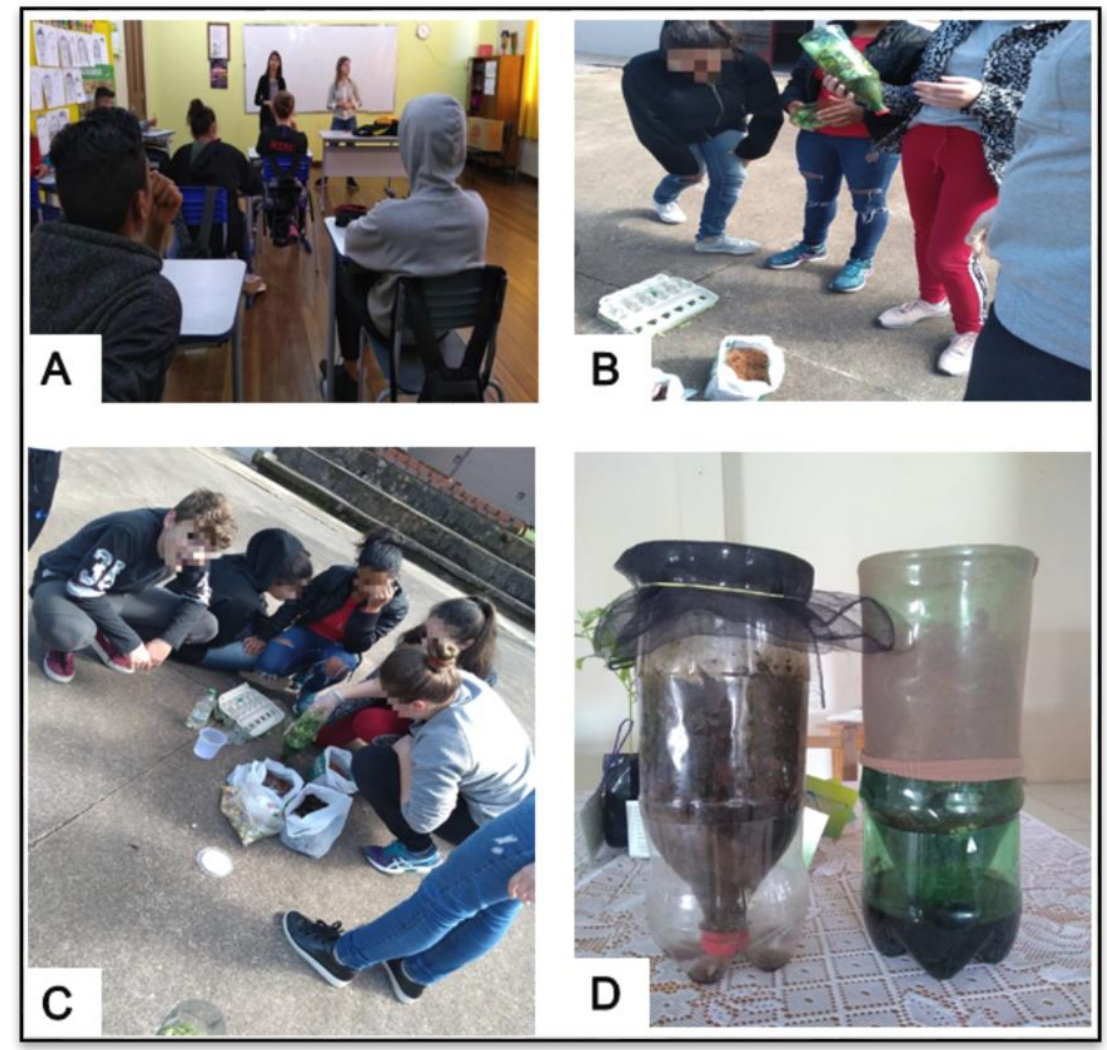

Figura 1 - Trabalhando a compostagem: etapa teórica (A), elaboração das composteiras (B/C) e as composteiras domésticas finalizadas (D). Fonte: Acervo das autoras (2019).

Também foi incentivada a construção de uma composteira na escola, com o aproveitamento dos próprios resíduos orgânicos produzidos na horta e com a merenda escolar. Objetivando reutilizar os resíduos orgânicos e produzir adubo para os alimentos produzidos na horta da escola.

As atividades foram realizadas de forma satisfatória e com participação ativa de todos os educandos, se consolidando enquanto uma ação de educação ambiental. Em diferentes momentos da oficina, tanto na etapa teórica quanto na prática, os educandos foram instigados a participar com diálogos ou questionamentos.

Observou-se muita curiosidade, principalmente, em relação às formas de como construir as composteiras e quais materiais, além dos trabalhados na oficina, poderiam ser utilizados. Os educandos relataram que a oficina somou muito ao aprendizado e contribuiu significativamente para o projeto desenvolvido por eles "Horta na escola". Afirmaram, que a compostagem era um processo desconhecido e que não havia sido trabalhado no projeto. Além disso, ficaram fascinados em saber que seria uma atividade

\begin{tabular}{lllll}
\hline Beling, Cancelier, Vestana & $e$ & de & ISSN 2594-9616 & 131 \\
Campos, 2020 & & & &
\end{tabular}


que poderiam desenvolver em suas residências e, que a partir desta, estariam contribuindo com a destinação correta dos resíduos orgânicos e um ambiente mais saudável.

Ao final do ano de 2019, após a realização da oficina e a partir dos conhecimentos assimilados, os educandos iniciaram auxiliados pelos professores de Geografia, Ciência e Matemática a construção da composteira na escola, a qual atenderá as demandas de adubo da própria horta da escola. Existe uma evidente preocupação entre os educandos em manter a horta, bem como, com a qualidade das hortaliças e verduras cultivadas, tendo em vista que, estas são destinadas para a merenda, o que permite melhorar a qualidade das refeições. Esses apontamentos reafirmam a preocupação que a escola tem em trabalhar de forma interdisciplinar questões relacionadas à preservação e manutenção do meio ambiente e assim melhorar a qualidade de vida da comunidade escolar.

Na oficina nomeada de "Colmeia da Sustentabilidade", desenvolveu-se através da Geografia, discussões em relação à sustentabilidade e importância das abelhas para o equilíbrio ambiental. Desta oficina participaram educandos de 4 a 9 anos de idade, o que exigiu a utilização de diferentes abordagens e estratégias de ensino e aprendizagem, entre as quais a realização de atividades lúdicas interativas.

Inicialmente, a partir de uma roda de conversa, os educandos foram questionados sobre sua participação no Projeto "O mel e suas utilidades". Sequencialmente, foi apresentado um vídeo que tratou do risco que as abelhas estão sofrendo em razão do uso indiscriminado de agrotóxicos, momento no qual as crianças foram instigadas a buscar soluções frente às questões socioambientais, aspectos importantes na construção de cidadãos conscientes. Levando em consideração a crescente utilização de agroquímicos e seus impactos ambientais, os quais estão diretamente relacionados à morte de milhões de abelhas no Rio Grande do Sul no ano de 2019, conforme anunciado pelo Campo e Lavoura (2019), se faz necessário trabalhar junto às escolas e suas comunidades atividades que venham a possibilitar o fortalecimento de práticas agroecológicas, bem como, a consolidação de sujeitos críticos, conscientes do papel de suas ações perante o meio ambiente.

A última etapa da oficina, de caráter prático, ocorreu a construção de enfeites utilizando materiais reutilizáveis, a elaboração de desenhos livres, desenhos para pintar, entre outras atividades. A imagem da figura 2 demonstra as fases da realização da oficina.

\begin{tabular}{lllll}
\hline Beling, Cancelier, Vestana & e de & ISSN 2594-9616 & 132 \\
Campos, 2020 & & & &
\end{tabular}




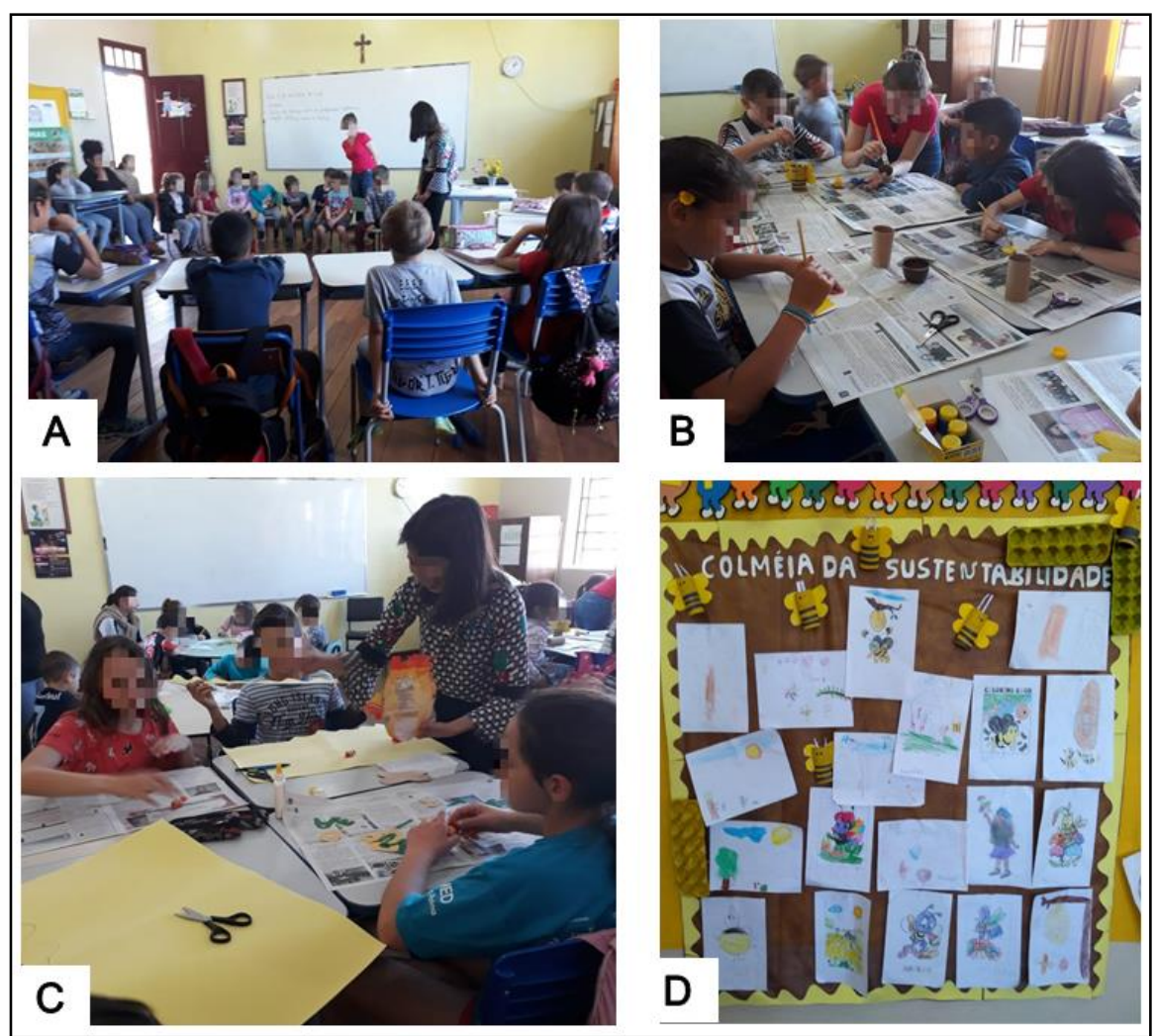

Figura 2 - Colmeia da sustentabilidade: roda de conversa (A), construção de enfeites e desenhos livres (B/C), e o mural com os resultados da oficina (D). Fonte: Acervo das autoras (2019).

Em todas as atividades realizadas houve significativo envolvimento dos educandos. Na roda de conversa, os questionamentos levantados sobre a importância das abelhas e seu papel para a manutenção ambiental foram respondidos. A contribuição ocorreu no sentido, de que estes tivessem maiores informações a respeito da importância das abelhas ao meio ambiente, tendo em vista que estas, só estão presentes em espaços onde as condições ambientais são propicias a sua sobrevivência e permanência.

$\mathrm{Na}$ etapa prática, foi expressiva a motivação dos educandos, principalmente quando construíram enfeites com materiais recicláveis, surgindo inclusive o interesse em construir brinquedos com materiais que normalmente iriam para o lixo. A partir da exposição no mural dos trabalhos realizados na oficina, os participantes se sentem valorizados pelas atividades realizadas. Ao colocar os trabalhos em evidência, a escola possibilita que o conhecimento se dissemine e desperte o interesse de outras crianças e jovens.

\begin{tabular}{lllll}
\hline Beling, Cancelier, Vestana & $e$ & de & ISSN 2594-9616 & 133 \\
Campos, 2020 & & & &
\end{tabular}


Nas oficinas, observou-se que as atividades realizadas em espaços ao ar livre motivam os alunos. O contato com a natureza, como pátios, jardins, horta e ações práticas, intensificam a construção do conhecimento e o respeito com a natureza, na medida em que, instigam o interesse pelo aprendizado sobre meio ambiente. Especificamente no ensino da Geografia as atividades práticas podem contribuir significativamente na compreensão dos estudos ambientais, potencializando a formação de sujeitos críticos e atuantes perante a realidade vivida. Trabalhar na escola a Geografia vinculada a Educação ambiental é possibilitar que o educando compreenda que o resultado materializado no meio ambiente é resultante das relações econômicas, sociais e culturais, que se manifestam de distintas formas entre as sociedades.

Ações como as oficinas realizadas buscam problematizar tais relações, na medida em que permitem ao educando que, desde criança, compreenda a importância da preservação do meio ambiente e seu papel como agente da transformação. Além disso, as práticas conseguiram aflorar um sentimento de pertencimento e valorização ao meio em que vivem. $\mathrm{O}$ fato de a escola estar inserida no espaço rural e possuir maior proximidade com a natureza é favorável para o processo de educação ambiental, pois os educandos percebem que precisam valorizar e manter o meio ambiente em que vivem.

\section{CONSIDERAÇÕES FINAIS}

A educação ambiental deve estar presente de forma articulada em todos os níveis do processo educativo. A escola é um ambiente ideal para auxiliar no desenvolvimento da consciência ambiental, na medida em que, é o centro de formação educacional dos sujeitos, local de muitos ensinamentos, trocas e construção do conhecimento. É um espaço oportuno para ensinamentos, práticas e reflexões sobre a educação ambiental, cidadania e conservação, na intenção de formar cidadãos sensibilizados, conscientes, críticos e atuantes frente às questões socioambientais.

Nesse sentido, práticas e ações pedagógicas como as oficinas realizadas motivam os alunos na construção do conhecimento e potencializam as reflexões acerca da educação ambiental. O trabalho interdisciplinar frente à temática ambiental possibilita a ampliação do entendimento da temática, produzindo conhecimentos científicos e socioambientais.

\begin{tabular}{llllll}
\hline Beling, Cancelier, & Vestana & $e$ & de & ISSN 2594-9616 & 134 \\
Campos, 2020 & & & & &
\end{tabular}


A educação ambiental deve ser trabalhada de maneira efetiva, consciente e articulada com a realidade dos educandos, realizando relações com outras escalas. Auxiliando no desenvolvimento da autonomia, do pensar crítico, da criatividade e da intervenção dos educandos em sua realidade de vivência e de convivência. São fundamentais práticas e ações que envolvam a comunidade escolar, a partir disto, buscar alternativas para os problemas que ocorrem no espaço de vivência e de convivência, de trabalho e vida, onde as relações sociais, ambientais, econômicas e culturais se estabelecem.

No que diz respeito ao ensino de Geografia e a Educação ambiental, é necessário problematizar as relações entre o meio ambiente e os grupos sociais, auxiliando na construção de uma visão crítica e na busca de uma sociedade mais justa e sustentável.

\section{REFERÊNCIAS}

BOTÊLHO, L, A, V; et al. A educação ambiental e a geografia escolar: dimensões curriculares, possibilidades e desafios contemporâneos. Revista Caminhos de Geografia. v. 17, n. 59. Setembro/2016. Uberlândia, MG. Disponível em: <http://www.seer.ufu.br/index.php/caminhosdegeografia/article/view/31858> Acesso em: abr. de 2020.

BRAGA, R. de O. B. Algumas práticas no ensino de geografia. X Congresso Nacional de Educação. Pontifícia Universidade Católica do Paraná. Curitiba, PR. 2011. pag. 12944-12.951. Disponível em: <http://www.seer.ufu.br/index.php/caminhosdegeografia/article/view/31858> Acesso em: abr. de 2020.

BRASIL. Constituição da República Federativa do Brasil, 1988. Brasília: Senado Federal. Disponível em: <http://portal.mec.gov.br/seb/arquivos/pdf/meioambiente.pdf>. Acesso em: 28 fev. de 2020.

BRASIL. Diretrizes Curriculares Nacionais para a Educação Ambiental. Brasília, $2012 . \quad$ Disponível em: $<$ http://portal.mec.gov.br/index.php?option=com_docman\&view=download\&alias=109 55-pcp014-12\&Itemid=30192>. Acesso em: 11 de fev. de 2020.

BRASIL. Lei $\mathrm{n}^{\circ}$ 9.394, de 20 de dezembro de 1996. Lei de Diretrizes e Bases da Educação Nacional. Diário Oficial da União, Brasília, DF. Disponível em: <http://portal.mec.gov.br/seb/arquivos/pdf/meioambiente.pdf>. Acesso em: $18 \mathrm{fev}$. de 2020.

\begin{tabular}{llllll}
\hline Beling, & Cancelier, Vestana & $e$ & de & ISSN 2594-9616 & 135
\end{tabular}

Campos, 2020 
BRASIL. Parâmetros Curriculares Nacionais: meio ambiente. Brasília/DF, 1997. Disponível em: <http://portal.mec.gov.br/seb/arquivos/pdf/meioambiente.pdf>. Acesso em: 08 mar. de 2020.

BRASIL. Lei n ${ }^{\circ}$ 9.795, de 27 de abril de 1999. Política Nacional de Educação Ambiental. Diário Oficial da União, Brasília, DF. Disponível em: <http://www.planalto.gov.br/ccivil_03/LEIS/L9795.htm>. Acesso em: 20 jan. de 2020.

CALLAI, H. C. O município: uma abordagem geográfica nos primeiros anos da formação básica. In: CAVALCANTI, L. de S.. Temas da Geografia na escola básica. Campinas, SP: Papirus, 2013.

CAMPO E LAVOURA. Laudo mostra que agrotóxicos causaram morte de milhões de abelhas no 2019.2 DS. 2 Disponível em <https://gauchazh.clicrbs.com.br/economia/campo-e-lavoura/noticia/2019/07/laudomostra-que-agrotoxicos-causaram-morte-de-milhoes-de-abelhas-no-rscjyhei8yp008701k0q6pdxkpm.html> Acesso em: 15 fev. de 2020

CAVALCANTI, L. de S. Concepções teórico-metodológicas da Geografia escolar no mundo contemporâneo e abordagens no ensino. In: SANTOS. L. C. P. etall. (orgs). Convergências e tensões no campo da formação e do trabalho docente. Belo Horizonte: Autentica, 2010.

CARVALHO, I. C. M. Questão ambiental e a emergência de um campo de ação políticopedagógico. In: LOUREIRO, C. F. B.; LAYRARGUES, P. P.; CASTRO, R. S. (Org.). Sociedade e meio ambiente. São Paulo: Cortez, 2000. p. 53-65.

FERRAZ, C, B, O. A geografia da educação na sociedade do conhecimento: sombras do desconhecimento. Ensino de Geografia: Novos olhares e práticas. Editora UFGD, Universidade Federal de Grande Dourados. Dourados, MS. 2011. Disponível: <http://209.177.156.169/libreria_cm/archivos/pdf_56.pdf> Acesso em: abr. de 2020.

FERREIRA, A. A; et al. A importância da prática de ensino em geografia. IV Encontro Estadual de didática e práticas de ensino. Centro de Estudos e Pesquisas em Didática (CEPED). ANAIS. Goiânia, GO. 2011. Disponível: <http://cepedgoias.com.br/edipe/ivedipe/pdfs/geografia/co/114-187-1-SM.pdf>. Acesso em: abr. de 2020.

FREIRE, P. Pedagogia da autonomia: saberes necessários à prática educativa. 22. ed. São Paulo: Paz e Terra, 2002.

GUIMARÃES, M. A Formação de educadores ambientais em tempo de crise. In: XI Congresso Nacional de Educação-Educere. Curitiba, p. 30371 - 30372, 2013. Disponível em: <https://educere.bruc.com.br/arquivo/pdf2013/15621_7212.pdf> Acesso em: 17 jan. de 2020.

Beling, Cancelier, Vestana $e$ de $\quad$ ISSN 2594-9616 136


MORAIS, E. M. B. de. As temáticas físico-naturais no ensino de geografia. In: CAVALCANTI, Lana de Souza. Temas da Geografia na escola básica. Campinas, SP: Papirus, 2013.

NETO LANDIM, F, O; BARBOSA, M, E, S. O ensino de geografia na educação básica: uma análise da relação entre a formação do docente e sua atuação na Geografia escolar. Revista Geosaberes - v. 1, n. 2, Dezembro/2010. Universidade Federal do Ceará. Disponível em: <http://cepedgoias.com.br/edipe/ivedipe/pdfs/geografia/co/114-187-1SM.pdf> Acesso em: 03 abr. de 2020.

PONTUSCHKA, N. N.; PAGANELLI, T. I.; CACETE, N. H. Para ensinar e aprender Geografia. 3 ed. São Paulo: Cortez, 2009.

PPP, Projeto Político Pedagógico. Escola Estadual de Ensino Fundamental Dom Érico Ferrari. Nova Palma: PPP, 2017.

STEFANELLO, C. F. R; DELlA MÉA, J. A. C. Projeto “O mel e suas utilidades”. Escola Estadual de Ensino Fundamental Dom Érico Ferrari. Nova Palma, RS. Inédito. 2019.

TOZONI-REIS, M. F. C. Metodologias aplicadas à educação ambiental. Curitiba: IESD Brasil, 2008.

TURRA, A. Projeto "Horta na escola". Escola Estadual de Ensino Fundamental Dom Érico Ferrari. Nova Palma, RS. Inédito. 2019.

\footnotetext{
${ }^{\mathrm{i}} \mathrm{O}$ objetivo principal desse projeto foi desenvolver nos educandos habilidades de trabalho em equipe, organização e planejamento através da construção de uma horta escolar proporcionando ao aluno utilizar seu tempo livre na aquisição de técnicas e conhecimento que resultem na melhoria de sua qualidade de vida e auxilie no enriquecimento da merenda escolar através da produção de hortaliças (TURRA, 2019).

ii Esse projeto teve como objetivo central desenvolver a consciência ambiental nos educandos, por meio do conhecimento da vida das abelhas, seus valores e curiosidades e colocar em prática conceitos, procedimentos e atitudes desenvolvidas no aprendizado escolar, nas disciplinas do currículo, contando com a abelha Jataí, o mel e a produção dos seus derivados (STEFANELLO; DELLA MÉA, 2019).
} 